\section{(A) Check for updates}

Cite this: Dalton Trans., 2019, 48, 3415

Received 25th September 2018, Accepted 12th February 2019

DOI: 10.1039/c8dt03866j

rsc.li/dalton

\title{
Towards highly active and stable nickel-based metal-organic frameworks as ethylene oligomerization catalysts $\uparrow$
}

\author{
Ubed S. F. Arrozi, Volodymyr Bon, (D) Christel Kutzscher, Irena Senkovska (D) and \\ Stefan Kaskel (DD*
}

\begin{abstract}
Catalytic ethylene oligomerization proceeds under mild conditions with high activity using porous or non-porous nickel-based coordination polymers/metal-organic frameworks (MOFs) as catalysts. The role of MOFs as catalyst precursors and the crucial impact of metal coordination on the catalyst activity and leaching are elucidated by comparing MOFs constructed from different clusters and linkers. The stronger the coordination bond of organic linkers to the Ni center, the lower the catalytic activity of the MOF, as shown for CPO-27(Ni). The highest activity and stability were obtained with the $\left[\mathrm{Ni}_{3}(\mathrm{ndc})_{3}(\mathrm{DMF})_{2}\left(\left(\mathrm{CH}_{3}\right)_{2} \mathrm{NH}\right)_{2}\right]_{n}$ catalyst.
\end{abstract}

\section{Introduction}

The selective oligomerization of ethylene towards $\mathrm{C}_{4}-\mathrm{C}_{20}$ linear $\alpha$-olefins (LAOs) attracts considerable interest due to the growing industrial demand. ${ }^{1}$ These are notably used as comonomers with ethylene to produce linear low-density polyethylene (LLDPE), synthetic lubricants $\left(\mathrm{C}_{10}\right)$, additives for high-density polyethylene $\left(\mathrm{C}_{6}-\mathrm{C}_{10}\right)$, and surfactants $\left(\mathrm{C}_{12}-\mathrm{C}_{20}\right){ }^{2}$ The oligomerization of ethylene is industrially applied by employing homogeneous or heterogeneous catalysts comprising transition metals (e.g. Ni, Ti, Cr, Fe, and $\mathrm{Pd}$ ) with tailored activity and selectivity by engineering the coordination sphere of the active site. ${ }^{3}$ In the catalytic cycle of ethylene oligomerization, the $\mathrm{Ni}^{2+}$ catalysts are apt to favor chain termination over propagation; hence oligomers are more favorably formed than polymers. ${ }^{4}$ Such premises are ideally suited for heterogeneous porous catalysts with a high surface area, since the active sites continue to be accessible while pore blocking by the formation of polymers inside the pores is supressed. ${ }^{5}$

From an industrial viewpoint, heterogeneous catalysts are environmentally friendly compared to homogeneous counterparts, as catalyst separation from the reaction products is facilitated, resulting in reduced solvent waste. Furthermore, heterogeneous catalysts also show effectively reduced reactor fouling in olefin oligomerization catalysis. ${ }^{6}$ Established catalyst supports include $\mathrm{SiO}_{2},{ }^{7} \mathrm{Al}_{2} \mathrm{O}_{3},{ }^{8}$ and zeolites. ${ }^{9}$ Recently,

Technische Universität Dresden, Department of Inorganic Chemistry, Bergstraße 66, D-01062 Dresden, Germany.E-mail: stefan.kaskel@tu-dresden.de

$\dagger$ Electronic supplementary information (ESI) available. See DOI: 10.1039/ c8dt03866j metal-organic frameworks (MOFs) have also been proposed, offering a high surface area and active metal sites simultaneously. ${ }^{10,11}$ Their modular structure and tunable pore environment offer various benefits compared to other catalyst supports as the homogeneous transition metal complex is part of the intrinsic network structure within a well-defined structure of the heterogeneous catalyst. In addition, the high inner surface area of MOFs facilitates tailoring of the active site accessibility during catalytic cycles via pore size engineering. Considering all of these advantages, MOFs are highly promising as catalysts for organic transformations including the oligomerization of light olefins, either by using the metal centers in the MOF structures as active sites ${ }^{10}$ or by modifying MOFs to insert certain active species into the pores. ${ }^{11}$

One example of employing metal centers as active sites is MIL-100(Cr), reported by Liu et al., showing moderate activity towards ethylene oligomerization and the selectivity of oligomer distribution depending on the activation temperature, which influences the reduction of $\mathrm{Cr}^{3+}$ to $\mathrm{Cr}^{2+} \cdot{ }^{10 a}$ Furthermore, Long and co-workers showed that unsaturated nickel centers in the structure of $\mathrm{CPO}-27(\mathrm{Ni})$ are able to transform ethylene and propylene into their linear oligomers with higher selectivity compared to a nickel modified zeolite in gas phase reactions, despite possessing lower activity compared to Ni-Na-MCM-41. ${ }^{10 b}$ Moreover, the active sites can be even selectively inserted into the catalytically inert metal clusters as it was shown for NU-1000, ${ }^{11 e} \mathrm{MFU}-4,{ }^{11 f, g}$ or MOF-808. ${ }^{11 h}$ Also, the incorporation of active species into organic linkers which has been shown in immobilized nickel species in the architecture of IRMOF-3, ${ }^{11 a}$ MIL-101(Fe), ${ }^{11 b}$ UiO-67(bpydc), ${ }^{11 c}$ and NU-1000 ${ }^{11 d}$ is an effective approach to produce MOFs with 
high activity in the catalytic reaction of ethylene oligomerization/polymerization. However, with the increasing efforts and strategies to design MOFs as active catalysts for this reaction, the fundamental aspects of catalyst stabilities which impact on the catalyst's activity and lifetime remain to be investigated.

Insights into structure-property relationships are achieved by employing MOFs with well-distributed active sites and a uniform coordination environment. We are interested to achieve a better understanding of the impact of varying Ni metal clusters, as well as the role of variations in the linker surrounding in the same $\mathrm{Ni}$ cluster, on the ethylene oligomerization reaction.

Therefore several Ni-based MOFs (Table 1), containing four different inorganic building units and possessing different porosities, namely $\left[\mathrm{Ni}_{2}(\mathrm{dhtp})\right]_{n}(\mathbf{1} ; \mathrm{CPO}-27(\mathrm{Ni}) ;$ Fig. $1 \mathrm{a}) ;^{12 a}$ $[\mathrm{Ni}(\mathrm{bdc})(\text { dabco })]_{n}{ }^{12 b}$ (2; Fig. 1b) (bdc = 1,4-benzenedicarboxylate, dabco $=1,4$-diazabicyclo[2.2.2] octane); $\left[\mathrm{Ni}_{3}(\text { ndc })_{3}(\mathrm{DMF})_{2}\right.$ $\left.\left(\left(\mathrm{CH}_{3}\right)_{2} \mathrm{NH}\right)_{2}\right]_{n}$ (3; Fig. 1c) (ndc = 2,6-naphthalenedicarboxylate, DMF $=N, N$-dimethylformamide $) ;{ }^{12 c, d}\left[\mathrm{Ni}(\mathrm{L})(\text { dabco })_{0.5}\right]$ with $\mathrm{L}=$ bdc (4; Fig. 1d); ${ }^{12 b} \mathrm{~L}=\operatorname{ndc}\left(\mathbf{5}, \mathbf{6}\right.$; DUT-8(Ni); Fig. 1e); ${ }^{12 c, e}$ and $\mathrm{L}=$ bpdc $\left(\right.$ bpdc $=4,4^{\prime}$-biphenyldicarboxylate $(7 ;$ DUT-128; Fig. 1f), were synthesized and characterized for further investigations of their performances as catalysts in the ethylene oligomerization reaction in the presence of $\mathrm{Et}_{2} \mathrm{AlCl}$ as the cocatalyst. While the compounds $4,5,6$ and 7 have the same paddle wheel cluster, 5/6 and 7 are isoreticular, differing in the linker lengths.

\section{Results and discussion}

The selected MOFs were synthesized by adapting previously reported procedures. The identification and phase purity analysis of all synthesized MOFs were performed by powder X-ray diffraction (PXRD) (Fig. S1-S5 and S16†), ATR-IR (Fig. S7$\mathrm{S} 12 \dagger)$, and elemental analysis. The crystal size of the obtained compounds estimated by scanning electron microscopy (SEM) analyses varies from 0.5 to $125 \mu \mathrm{m}$ (Fig. S6†). The Ni-based MOF structures and the corresponding metal nodes as well as organic linkers are shown in Fig. 1.

The coordination environment of $\mathrm{Ni}^{2+}$ in the structure of $\mathbf{1}$ is composed of five oxygen atoms from the organic linker 2,5dihydroxyterephthalic acid while the remaining vacant sites at $\mathrm{Ni}^{2+}$ are occupied by solvent molecules which can be removed during thermal activation. ${ }^{12 a}$
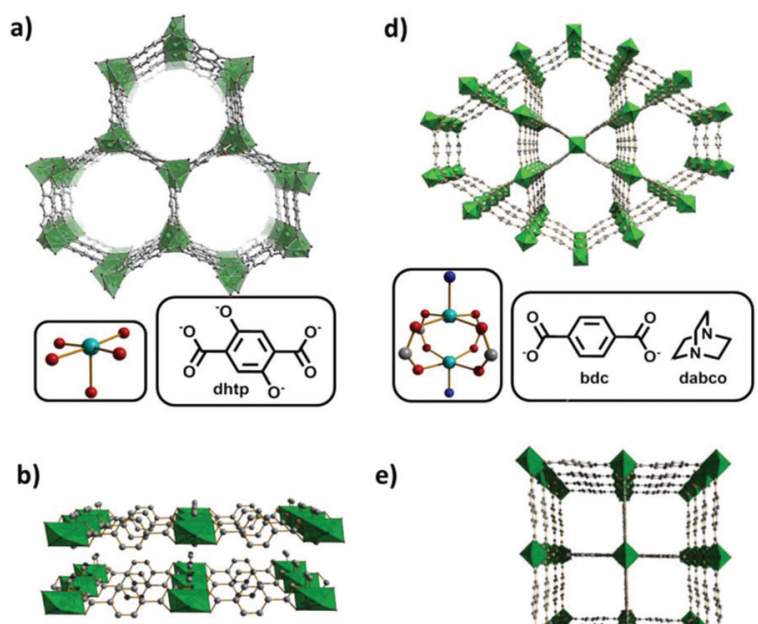

e)
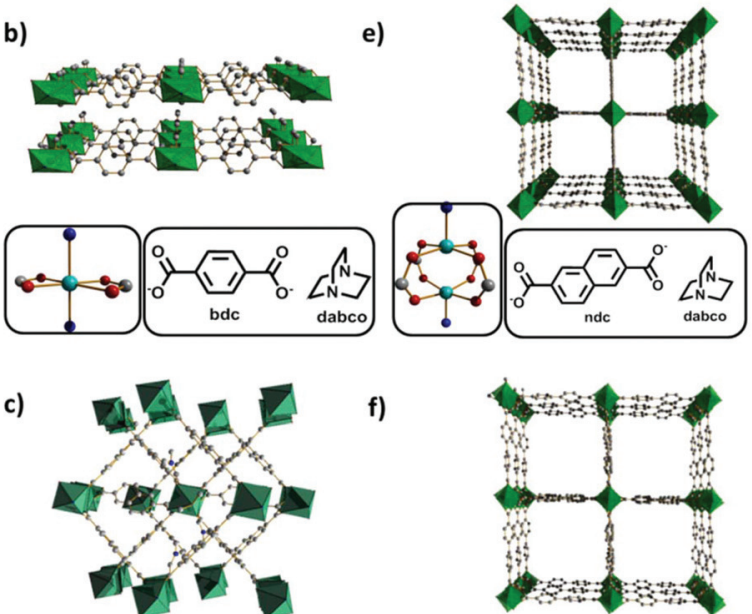

f)
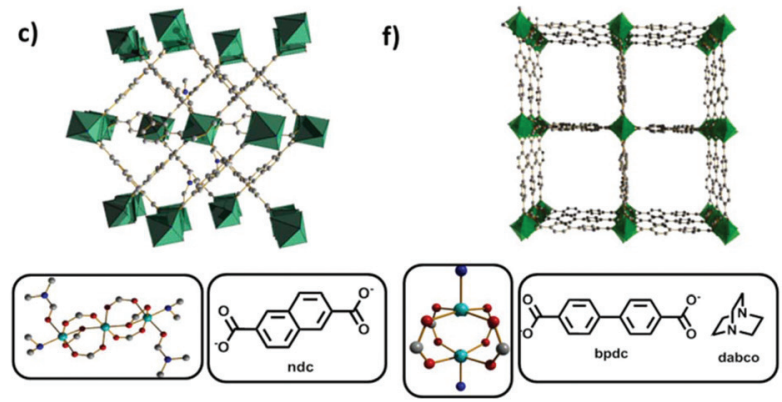

Fig. 1 Ni-Based MOF structures with the corresponding metal clusters and organic linkers: (a) $\left[\mathrm{Ni}_{2}(\mathrm{dhtp})\right]_{n}{ }^{12 a}$ (CPO-27(Ni), 1, CCDC 288477); (b) $[\mathrm{Ni}(\mathrm{bdc})(\mathrm{dabco})]_{n}{ }^{12 b}(2, \mathrm{CCDC} \quad 802894) ; \quad$ (c) $\left[\mathrm{Ni}_{3}(\mathrm{ndc})_{3}(\mathrm{DMF})_{2}\right.$ $\left.\left(\left(\mathrm{CH}_{3}\right)_{2} \mathrm{NH}\right)_{2}\right]_{n}{ }^{12 c, d}$ (3, CCDC 759306); (d) [Ni(bdc)(dabco $\left.)_{0.5}\right]_{n}{ }^{12 b}$ (4, CCDC 802893); (e) [Ni(ndc)(dabco $\left.)_{0.5}\right]_{n}$ (DUT-8(Ni)) $)^{12 c, e}(5 / 6$, CCDC 760964); and (f) [Ni(bpdc)(dabco) $\left.)_{0.5}\right]_{n}$ (DUT-128, 7, CCDC 1835717).

The $2 \mathrm{D}$ coordination polymer 2 contains $\mathrm{NiO}_{4} \mathrm{~N}_{2}$ polyhedra coordinated to two carboxylic groups of terephthalate anions and two nitrogen atoms from dabco. ${ }^{12 b}$ Compound 3 is built up by linear trimeric $\mathrm{Ni}_{3}$ clusters linked by six carboxylic groups from the ndc ligands to form a neutral, dense $3 \mathrm{D}$ network. The remaining coordination places on the $\mathrm{Ni}_{3}$-cluster are saturated by two terminal DMF and dimethylamine

Table 1 Selected Ni-MOFs ${ }^{a}$

\begin{tabular}{|c|c|c|}
\hline Composition & Name & Pore volume $/ \mathrm{cm}^{3} \mathrm{~g}^{-1}$ \\
\hline$\left[\mathrm{Ni}_{2}(\mathrm{dhtp})\right]_{n}{ }^{12 a}(\mathbf{1})$ & $\mathrm{CPO}-27(\mathrm{Ni})$ & 0.5 \\
\hline$[\mathrm{Ni}(\mathrm{bdc})(\mathrm{dabco})]_{n}{ }^{12 b}(2)$ & - & 0.1 \\
\hline$\left[\mathrm{Ni}_{3}(\mathrm{ndc})_{3}(\mathrm{DMF})_{2}\left(\left(\mathrm{CH}_{3}\right)_{2} \mathrm{NH}\right)\right]_{n}{ }^{12 d}(3)$ & - & 0.02 \\
\hline$\left[\mathrm{Ni}(\mathrm{bdc})(\text { dabco })_{0.5}\right]_{n}{ }^{12 b}(4)$ & - & 0.9 \\
\hline$\left[\mathrm{Ni}(\mathrm{ndc})(\mathrm{dabco})_{0.5}\right]_{n \_}$rigid $^{12 c, d}(\mathbf{5})$ & DUT-8(Ni)_rigid & 0.9 \\
\hline$\left[\mathrm{Ni}(\mathrm{ndc})(\mathrm{dabco})_{0.5}\right]_{n-}$ flexible $^{12 c, e}(\mathbf{6})$ & DUT-8(Ni)_flexible & 1.0 \\
\hline$\left[\mathrm{Ni}(\text { bpdc })(\text { dabco })_{0.5}\right]_{n}(7)$ & DUT-128 & 0.8 \\
\hline
\end{tabular}

${ }^{a}$ The corresponding structures of the linkers involved are shown in Fig. 1. 
ligands. ${ }^{12 c, d}$ Both structures (2 and 3) are dense and show no crystallographic porosity.

Compound 4 forms 4-connected Kagome layers, constructed from Ni paddle wheels and bdc ligands, which are interconnected into a 3D framework by dabco. ${ }^{12 b}$ However, 5/6 (DUT-8(Ni)) and 7 (DUT-128) belong to the porous pillared layer DMOF family, based on $\mathrm{Ni}_{2}(\mathrm{COO})_{4}$ paddle wheels interlinked by four carboxylic linkers to layers and two nitrogen atoms from the dabco pillar, bridging the layers into a $3 \mathrm{D}$ framework with rectangular channels. ${ }^{12 c, e}$ DUT-8(Ni) was synthesized in two forms, flexible (6) and rigid (5), differing significantly in adsorption properties and crystallite size. ${ }^{12 c}$ While the DUT-8(Ni)_flexible (6) is able to undergo structural transformation from an open pore form into a closed pore form and vice versa, ${ }^{12 c}$ DUT-8(Ni)_rigid (5) is always in the open pore form.

Nitrogen physisorption experiments at $77 \mathrm{~K}$ (Fig. S13-S15 and Table $\mathrm{S} 1 \dagger$ ) show type Ia adsorption isotherms for $\mathbf{1 , 4}$, and 5. In contrast, compound 6 shows typical "gate opening" in the adsorption branch of the isotherm. ${ }^{12 c}$ Compounds 2 and 3 exhibit very low uptake of nitrogen as expected from the crystal structure.

DUT-128 (compound 7) was obtained by replacing $\mathrm{H}_{2}$ ndc by $\mathrm{H}_{2}$ bpdc in the synthesis procedure of the flexible version of DUT-8(Ni). Since single crystals suitable for structure determination could not be obtained, the experimental PXRD pattern of the product was compared with the calculated one, generated from a chiral DUT-128 analog, [Ni(L-proline-bpdc) $\left.(\text { dabco })_{0.5}\right]_{n}$, deposited in the CSD database. ${ }^{13}$ It suggests that both structures are isoreticular (Fig. S16 and S17†).

The ethylene oligomerization reaction of interest proceeds in toluene as the solvent in the presence of $\mathrm{Et}_{2} \mathrm{AlCl}$ as the co-catalyst. Therefore, the stability of selected MOFs towards $\mathrm{Et}_{2} \mathrm{AlCl}$ as highly reactive species ${ }^{14}$ was examined first. The MOFs were stirred in toluene in the presence of $\mathrm{Et}_{2} \mathrm{AlCl}$ overnight. According to the PXRD patterns (Fig. S1-S5 and S16†), compounds 1, 5, and 3 are more stable under these conditions than the other investigated Ni-MOFs which undergo structural transformation.

The evaluation of the catalytic performance for all Ni-MOFs was carried out with two different approaches. The first evaluation was performed in ethylene consumption experiments, recording the kinetic conversion profiles for each catalyst. For that matter, the activated catalysts, toluene and $\mathrm{Et}_{2} \mathrm{ACl}$ were stirred at $\mathrm{rt}\left(21{ }^{\circ} \mathrm{C}\right)$ under 11.8 bar ethylene pressure in a closed reactor system for $1 \mathrm{~h}$. The closed system without additional ethylene feed was monitored with respect to ethylene consumption (i.e. pressure drop). Fig. 2 shows that an immediate drop of ethylene pressure was observed in the first minute of the reactions for all catalysts as well as for the blank experiment without a catalyst due to the dissolving of ethylene in toluene. ${ }^{15}$ Comparing all Ni-MOFs as catalysts, it can be clearly seen that all Ni-MOFs were active toward ethylene oligomerization except 1, which shows only a slight decrease in ethylene pressure after $1 \mathrm{~h}$ of reaction. We hypothesize that although 1 has one vacant site available in the $\mathrm{Ni}^{2+}$ coordination environment, the chemical bonding of the organic

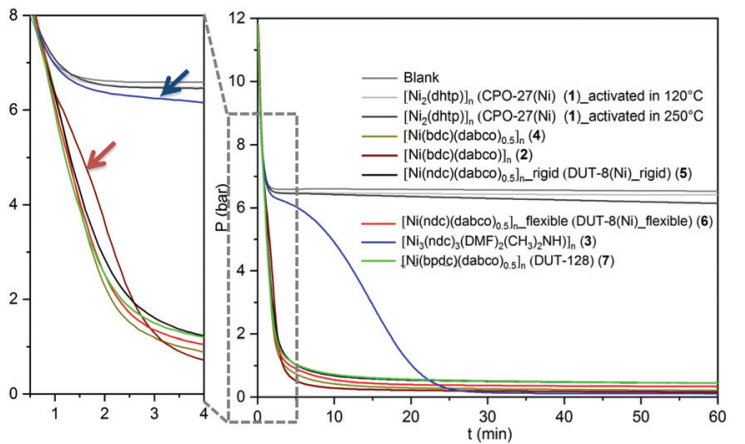

Fig. 2 Ethylene consumption during ethylene oligomerization reactions catalyzed by Ni-MOFs. The enlarged figure shows the induction period for $[\mathrm{Ni}(\mathrm{bdc})(\mathrm{dabco})]_{n}$ (2) and $\left[\mathrm{Ni}_{3}(\mathrm{ndc})_{3}(\mathrm{DMF})_{2}\left(\left(\mathrm{CH}_{3}\right)_{2} \mathrm{NH}\right)_{2}\right]_{n}$ (3) catalysts.

linker to $\mathrm{Ni}^{2+}$ is stronger than in the other $\mathrm{Ni}-\mathrm{MOFs}^{16}$ to provide an additional vacant site for initiating the reaction. Consequently, $\mathrm{Ni}^{2+}$ in the $\mathbf{1}$ structure is not able to mediate the catalytic reaction since the ethylene oligomerization/polymerization reaction mechanism requires two coordinative vacancies in an active site. ${ }^{4 c, 11 g, 17}$ The strong metal-ligand interaction in $\mathbf{1}$ is also reflected in the high stability observed during the stability test with $\mathrm{Et}_{2} \mathrm{AlCl}$. Both the non-porous structures 2 and 3, interestingly, show an induction period in opposition to other Ni-MOFs. This might be attributed to the less accessibility of $\mathrm{Ni}^{2+}$ in the non-porous MOFs compared to the porous ones as well as the higher barrier of the activation step of Ni-clusters by $\mathrm{Et}_{2} \mathrm{AlCl}$. However, both non-porous $\mathrm{Ni}$ MOFs are able to catalyze the reaction as shown by ethylene consumption after $1 \mathrm{~h}$ of reaction.

In further experiments, catalytic reactions were performed by maintaining the ethylene pressure for $1 \mathrm{~h}$ in order to analyze the reaction products by means of GC-MS analysis. As shown in Table 2, compound 1 (CPO-27(Ni)) has the lowest activity compared to other Ni-MOFs and butenes were the only detected reaction products, confirming the results of the ethylene consumption experiment. On the other hand, the pillared type Ni-MOFs $\left[\mathrm{Ni}(\mathrm{L})(\text { dabco })_{0.5}\right]_{n}$ exhibit almost similar intrinsic activities of 41 per mmol Ni per h (for 4), 42 per mmol Ni per h (for 5), and 49 per mmol Ni per $\mathrm{h}$ (for 7 ), with $\mathrm{C}_{4}$ and $\mathrm{C}_{6}$ as the main products and no polymeric product was observed (Table 2).

A slight difference in catalytic activity was observed for the two types of DUT-8(Ni) catalysts (compounds 5 and 6, Table 2, entries 5 and 8). This modest difference in catalytic activity could be attributed to the bigger crystallite size of 6 than that of 5, thus resulting in a slightly lower activity for the flexible one. The flexible behavior of DUT-8(Ni)_flexible does not affect the catalytic activity because the immersion of activated DUT-8 (Ni)_flexible (closed pore form) in toluene results in the open pore form (Fig. S4†). It indicates that both DUT-8(Ni) compounds are present in the same open pore form during the catalysis. Both the non-porous solid catalysts 2 and 3 show activities (41 and 49 per mmol Ni per h, respectively) similar to $\left[\mathrm{Ni}(\mathrm{L})(\text { dabco })_{0.5}\right]_{n}$ (Table 2). 
Table 2 Ethylene oligomerization catalyzed by Ni-MOFs ${ }^{a}$

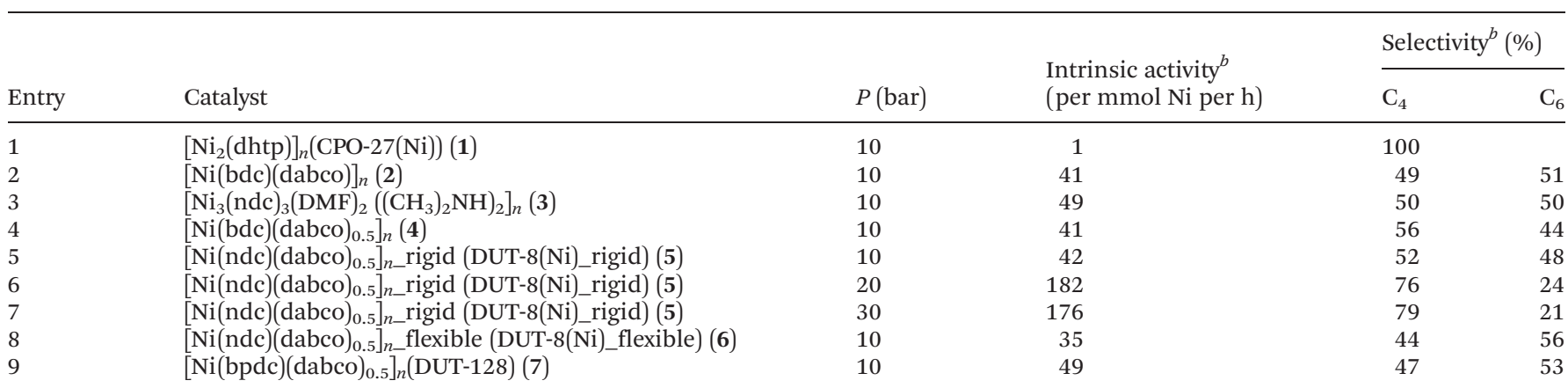

${ }^{a}$ Reactions were carried out in $10 \mathrm{ml}$ toluene with $22 \mu \mathrm{mol}$ nickel and in the presence of $\mathrm{Et}_{2} \mathrm{AlCl}$ as the co-catalyst $(\mathrm{Al} / \mathrm{Ni}=17)$ at room temperature $\left(21^{\circ} \mathrm{C}\right) .{ }^{b}$ Estimated selectivity based on GC analysis and calculated as the amount of the substance of oligomers formed (in mol) per mol Ni per h.

Considering the high activity and porosity as well as relative stability towards $\mathrm{Et}_{2} \mathrm{AlCl}$, DUT-8(Ni)_rigid (5) was used as the catalyst to further study the influence of ethylene pressure on the catalyst activity and selectivity. Entries 5-7 in Table 2 depict that increasing the ethylene pressure results in an increase of activity ( 42 and 182 per mmol Ni per h for 10 and 20 bar, respectively) as well as selectivity toward shorter oligomers (Fig. S18 ${ }^{\dagger}$ ). The intrinsic activity of $\mathbf{5}$ as the catalyst reaches a plateau at 30 bar (176 per mmol Ni per h) with a similar product selectivity achieved at 20 bar ethylene. The selectivity towards shorter oligomers with increasing pressure might be due to the fact that at given reaction conditions the higher ethylene pressure leads to an increase of the ethylene concentration in the solution, thus supporting the termination step of olefins that are coordinated to $\mathrm{Ni}^{2+}$ rather than chain propagation, resulting in more selectivity towards shorter chain oligomers.

Unfortunately, DUT-8(Ni)_rigid (5) undergoes a decomposition accompanied by the reduction of $\mathrm{Ni}^{2+}$ to the nickel metal $\left(\mathrm{Ni}^{0}\right)$ during the catalytic reaction (Fig. $\left.3 \mathrm{~b}\right)$. This motivated us to further study the active and stable $\left[\mathrm{Ni}_{3}(\text { ndc })_{3}(\mathrm{DMF})_{2}\left(\left(\mathrm{CH}_{3}\right)_{2} \mathrm{NH}\right)_{2}\right]_{n}$ (3) as the catalyst. The PXRD analysis of 3 after the catalytic reaction shows that the MOF retains the crystallinity (Fig. 3d) indicating that the structure of 3 remains intact.

The different stabilities of $\mathbf{5}$ and $\mathbf{3}$ may be reflected in the catalyst's lifetime. Therefore, both compounds were subjected to the cyclic ethylene oligomerization experiment where the ethylene consumptions were monitored. As a benchmark catalyst, a nickel $\alpha$-diimine complex, $\left[\mathrm{NiCl}_{2}\right.$ (bpy)] (bpy = 2,2'-bipyridine), was selected as it is known to be an active catalyst for ethylene oligomerization. ${ }^{18}$ During 5 cycles of ethylene oligomerization, $\left[\mathrm{NiCl}_{2}(\mathrm{bpy})\right]$ and $\mathbf{3}$ show a gradual increase of ethylene consumption in the first minute of reactions after each cycle (Fig. 4a and b). This is most likely caused by the increasing ethylene solubility in the reaction solution which already contains oligomers formed in the previous cycle. Moreover, the final ethylene pressure for both catalysts was almost similar after the fifth cycle $(1.24$ and 1.38 bar for $\left[\mathrm{NiCl}_{2}(\mathrm{bpy})\right]$ and 3 , respectively) showing that both catalysts

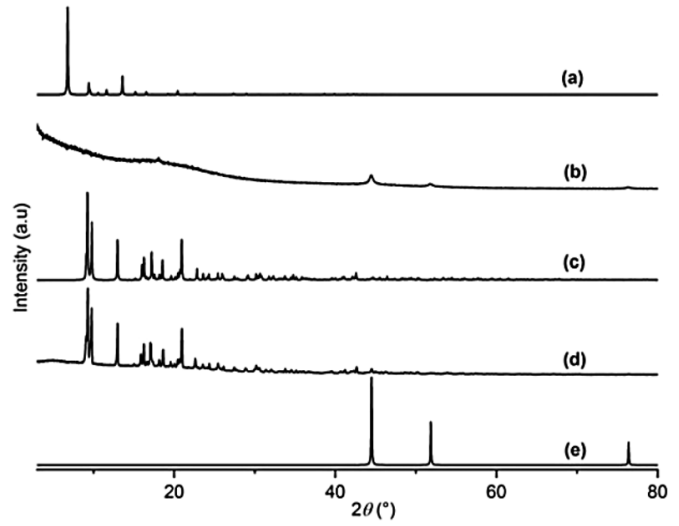

Fig. 3 (a) Theoretical pattern calculated from the crystal structure of the open pore form of DUT-8(Ni) (CCDC 760964); (b) measured PXRD pattern of DUT-8(Ni)_rigid (5) after the reaction; (c) theoretical pattern calculated from the crystal structure of $\left[\mathrm{Ni}_{3}(\mathrm{ndc})_{3}(\mathrm{DMF})_{2}\left(\left(\mathrm{CH}_{3}\right)_{2} \mathrm{NH}\right)_{2}\right]_{n}$ (3) (CCDC 759306); (d) measured PXRD pattern of $\left[\mathrm{Ni}_{3}(\mathrm{ndc})_{3}(\mathrm{DMF})_{2}\left(\left(\mathrm{CH}_{3}\right)_{2} \mathrm{NH}\right)_{2}\right]_{n}$ (3) after the reaction; and (e) theoretical pattern calculated from the crystal structure of $\mathrm{Ni}^{\circ}$ (COD 1534892).

have almost similar activity and stability. In contrast, DUT-8 (Ni)_rigid (5) shows a stepwise decrease in activity over five cycles (Fig. 4c) and consequently the final pressure of ethylene in the fifth cycle is significantly higher ( 4.74 bar) than that for 3 catalysts. It is a clear indication that the decrease of the activity is caused by the fast reduction of $\mathbf{5}$ to $\mathrm{Ni}^{0}$. The gas chromatographic (GC) analyses of the resulting solutions after the reaction support this finding showing that the activities of $\left[\mathrm{NiCl}_{2}\right.$ (bpy)], 3, and 5 are 71, 59, and 41 per mmol Ni per h, respectively. Interestingly, despite $\left[\mathrm{NiCl}_{2}\right.$ (bpy)] having a slightly higher activity than the other catalysts, 3 shows higher selectivity towards $\mathrm{C}_{4}$ and $\mathrm{C}_{6}$ oligomers compared to $\left[\mathrm{NiCl}_{2}(\mathrm{bpy})\right]$ showing broad range oligomers up to $\mathrm{C}_{20}$ (Fig. $\mathrm{S} 19 \dagger$ ).

The heterogeneity of 3 as the catalyst was investigated in two independent experiments. Firstly, compound 3 was stirred in toluene and $\mathrm{Et}_{2} \mathrm{AlCl}$ without ethylene feed for $1 \mathrm{~h}$. After that, the catalyst was separated from the solution and the reac- 

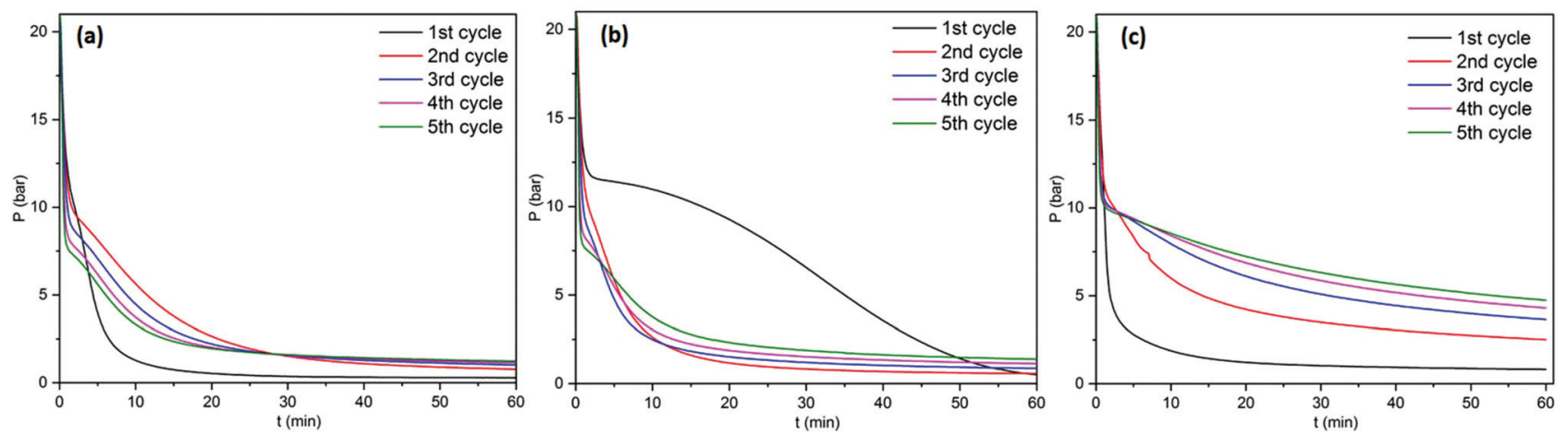

Fig. 4 Ethylene consumption with cyclic experiments catalyzed by (a) $\left[\mathrm{NiCl}_{2}(\mathrm{bpy})\right]$, (b) $\left[\mathrm{Ni}_{3}(\mathrm{ndc})_{3}(\mathrm{DMF})_{2}\left((\mathrm{CH})_{2} \mathrm{NH}_{2}\right]_{n}(3)\right.$ and (c) DUT-8(Ni)_rigid $(5)$.

tion was allowed to proceed under an ethylene pressure of 11.8 bar. The ethylene pressure only slightly decreases during $1 \mathrm{~h}$ of reaction (Fig. S20†) indicating a minimal leaching of active species from the structure. In an additional filtration test performed with 3 as the catalyst but under an ethylene atmosphere, a larger decrease in ethylene pressure was observed after catalyst filtration (Fig. S20 the formation and leaching of active species from 3 into the solution during the reaction. Nevertheless, the main catalytic activity can be attributed to the $\left[\mathrm{Ni}_{3}(\mathrm{ndc})_{3}(\mathrm{DMF})_{2}\left(\left(\mathrm{CH}_{3}\right)_{2} \mathrm{NH}\right)_{2}\right]_{n}$ (3) solid, since the ethylene consumption in the presence of MOFs is significantly higher.

Due to the fact that all $\mathrm{Ni}^{2+}$ atoms in the structure of $\left[\mathrm{Ni}_{3}(\mathrm{ndc})_{3}(\mathrm{DMF})_{2}\left(\left(\mathrm{CH}_{3}\right)_{2} \mathrm{NH}\right)_{2}\right]_{n}(3)$ are six-fold coordinated and no vacant coordination sites are available, an additional leaching test was performed to detect leaving ligands, which can be responsible for providing vacant nickel sites. For that the reaction was carried out at 1 bar ethylene pressure in deuterated toluene- $\mathrm{d}_{8}$ as the solvent for $3 \mathrm{~h}$. The ${ }^{1} \mathrm{H}$ NMR spectrum of the resulting solution (Fig. S21 $\dagger$ ) clearly shows the peaks of the oligomeric reaction products at 5.69, 4.88 and $4.82 \mathrm{ppm}$, demonstrating that the catalyst is also active even at low ethylene pressure. However, no leached organic ligands could be detected, probably due to the low solubility of the ligands in toluene. The alternative possibility is that the reaction takes place on the outer surface of the particles.

\section{Conclusion}

To conclude, we have presented a systematic study of the catalytic ethylene oligomerization reaction catalyzed by Ni-based MOFs. While CPO-27(Ni) (1) shows relatively low catalytic activity, all other investigated (porous and non-porous) $\mathrm{Ni}-$ based coordination polymers/MOFs exhibit high activity in the oligomerization of ethylene and possess higher selectivity toward shorter oligomers compared to the molecular $\alpha$-diimine catalyst $\left[\mathrm{NiCl}_{2}(\mathrm{bpy})\right]$. The porosity of the Ni-MOFs mainly affects the induction period of the reaction. The nonporous Ni-MOFs show a pronounced induction period which is not observed for the porous systems. The analysis of the impact of metal clusters in Ni-MOFs shows that the paddle wheel type nickel cluster and $\mathrm{NiO}_{4} \mathrm{~N}_{2}$ polyhedra cause higher reaction rates compared to the Ni-clusters of $\mathrm{CPO}-27(\mathrm{Ni})(\mathbf{1})$ and $\left[\mathrm{Ni}_{3}(\mathrm{ndc})_{3}(\mathrm{DMF})_{2}\left(\left(\mathrm{CH}_{3}\right)_{2} \mathrm{NH}\right)_{2}\right]_{n}$ (3) and also faster deactivation. These findings might be useful for designing highly active and stable MOFs as olefin oligomerization/polymerization catalysts in the future.

\section{Experimental}

\section{Materials and characterization methods}

All manipulations involving air and moisture-sensitive compounds were carried out under an argon atmosphere using either standard Schlenk or glove box techniques. All reagents were received and used without further purification. $\mathrm{Ni}\left(\mathrm{NO}_{3}\right)_{2} \cdot 6 \mathrm{H}_{2} \mathrm{O}(97 \%), \mathrm{Ni}\left(\mathrm{OCOCH}_{3}\right)_{2} \cdot 4 \mathrm{H}_{2} \mathrm{O}(98 \%), 1,4$-diazabicyclo[2.2.2] octane (99\%), diethylaluminum chloride solution (25 wt\% in toluene), 2,5-dihydroxyterephthalic acid (98\%), and 2,6-naphthalenedicarboxylic acid (99\%) were purchased from Sigma Aldrich. Terephthalic acid (99\%) was received from Acros Organics. 1-Butanol (99\%) was acquired from AppliChem Panreac. N,N-dimethylformamide (DMF) (99\%) was purchased from Fischer Chemical and toluene (99.8\%) of HPLC grade was obtained from Carl Roth.

A Stoe StadiP diffractometer with $\mathrm{Cu}_{\alpha 1}$ radiation $(\lambda=$ $1.5405 \AA$ ) and a 2D detector (Mythen, Dectris) was used to obtain powder X-ray diffraction (PXRD) patterns. All measurements were performed in transmission geometry using a rotating flatbed sample holder. The calculated PXRD patterns were obtained from CIF files using Mercury 3.10.2 software.

Nitrogen physisorption experiments were performed using a BELSORP-max apparatus at $77 \mathrm{~K}$ with a liquid nitrogen bath. All samples were activated at $120{ }^{\circ} \mathrm{C}$ prior to the adsorption measurements unless noted otherwise. Scanning electron microscopy (SEM) images were obtained using a ZEISS DSM-982 Gemini microscope. A Euro EA 3000 elemental analyzer was used to perform elemental analysis, and the sample was handled in air before elemental analysis measurement; therefore, some water might be absorbed. 
A Shimadzu GC 17A system equipped with a flame ionization detector (FID) and a BPX5 column (30 m length, $0.25 \mathrm{~mm}$ inner diameter, and $0.25 \mathrm{~mm}$ film thickness) was used for gas chromatography (GC) analyses. Product analyses were performed using a Shimadzu GC/MS system (QP5000 Mass Spectrophotometer) using the NIST database. The following temperature program was used in the GC measurements: samples were injected at a CG temperature of $32{ }^{\circ} \mathrm{C}$ and heated up to $48{ }^{\circ} \mathrm{C}$ with a heating rate of $4{ }^{\circ} \mathrm{C} \mathrm{min}^{-1}$. Afterwards, the temperature was increased to $100{ }^{\circ} \mathrm{C}$ with a heating rate $15^{\circ} \mathrm{C} \mathrm{min}^{-1}$ and a holding time of $4 \mathrm{~min}$. Finally, the temperature was increased to $300{ }^{\circ} \mathrm{C}$ with a heating rate and a holding time of $30^{\circ} \mathrm{C} \mathrm{min}^{-1}$ and $7 \mathrm{~min}$, respectively.

Microwave-assisted synthesis was performed using a CEM Discover microwave reactor system.

\section{Catalyst synthesis}

Synthesis of $\left[\mathbf{N i}_{2}(\mathbf{d h t p})\right]_{\boldsymbol{n}}(\mathbf{1})$. CPO-27(Ni) (1) was synthesized according to the previous published procedure. ${ }^{19}$ In a typical experiment, 2,5-dihydroxyterephthalic acid (1.194 g, $6 \mathrm{mmol}$ ) dissolved in $50 \mathrm{ml}$ 1-butanol was mixed with $\mathrm{Ni}\left(\mathrm{OCOCH}_{3}\right)_{2} \cdot 4 \mathrm{H}_{2} \mathrm{O}(2.986 \mathrm{~g}, 12 \mathrm{mmol})$ dissolved in $50 \mathrm{ml}$ distilled $\mathrm{H}_{2} \mathrm{O}$. The mixture was then stirred at $94{ }^{\circ} \mathrm{C}$ for 24 hours. The precipitate produced was decanted and washed with $300 \mathrm{ml}$ water, and then the solvent was exchanged with ethanol 6 times over 2 days. Finally, the brown powder was activated at $250{ }^{\circ} \mathrm{C}$ for 3 days to remove the coordinated ethanol. Yield: $1.514 \mathrm{~g}$ ( $80 \%$ based on $\left.\mathrm{H}_{2} \mathrm{dhtp}\right)$. Elemental analysis for $\left[\mathrm{Ni}_{2}\left(\mathrm{C}_{8} \mathrm{H}_{2} \mathrm{O}_{6}\right)\right] \cdot 0.8 \mathrm{H}_{2} \mathrm{O}$ calcd: $\mathrm{C} 29.48, \mathrm{H} \mathrm{1.12}$; found: $\mathrm{C}$ 29.47, H 1.14.

Synthesis of $[\mathrm{Ni}(\mathrm{bdc})(\text { dabco })]_{\boldsymbol{n}}$ (2). Compound $2^{12 b}$ was synthesized by mixing $\mathrm{Ni}\left(\mathrm{NO}_{3}\right)_{2} \cdot 6 \mathrm{H}_{2} \mathrm{O}(0.29 \mathrm{~g}, 1 \mathrm{mmol})$ dissolved in $3 \mathrm{ml} \mathrm{DMF}$, terephthalic acid $(0.083 \mathrm{~g}, 0.5 \mathrm{mmol})$ dissolved in $8.5 \mathrm{ml} \mathrm{DMF}$, and dabco $(0.196 \mathrm{~g}, 1.75 \mathrm{mmol})$ dissolved in $3.5 \mathrm{ml} \mathrm{DMF}$. The mixture was the stirred for 5 hours at $110{ }^{\circ} \mathrm{C}$. Solvent exchange and activation procedures were similar to those applied for $\left[\mathrm{Ni}(\mathrm{bdc})(\text { dabco })_{0.5}\right]$. Yield: $0.08 \mathrm{~g}$ (48\% based on $\mathrm{H}_{2}$ bdc). Elemental analysis for $\left[\mathrm{Ni}\left(\mathrm{C}_{8} \mathrm{H}_{4} \mathrm{O}_{4}\right)\right.$ $\left.\left(\mathrm{C}_{6} \mathrm{H}_{12} \mathrm{~N}_{2}\right)\right] \cdot 1.4 \mathrm{H}_{2} \mathrm{O}$ calcd: $\mathrm{C} 46.68, \mathrm{H} 5.26, \mathrm{~N} 7.86$; found: $\mathrm{C}$ 46.03, H 4.56, N 8.06.

Synthesis of $\left[\mathrm{Ni}_{3}(\mathrm{ndc})_{3}(\mathrm{DMF})_{2}\left(\left(\mathrm{CH}_{3}\right)_{2} \mathbf{N H}\right)_{2}\right]_{n}$ (3). The synthesis was performed by adapting the procedures reported in ref. $12 c$. Yield: $0.177 \mathrm{~g}$ (36\% based on $\mathrm{H}_{2}$ ndc). Elemental analysis for $\left[\mathrm{Ni}_{3}\left(\mathrm{C}_{12} \mathrm{H}_{6} \mathrm{O}_{4}\right)_{3}\left(\mathrm{C}_{3} \mathrm{H}_{7} \mathrm{NO}\right)_{2}\left(\left(\mathrm{CH}_{3}\right)_{2} \mathrm{NH}\right)_{2}\right]$ calcd: C 52.37, $\mathrm{H}$ 4.39, N 5.31; found: C 52.69, H 3.99, N 5.27.

Synthesis of $\left[\mathrm{Ni}(\text { bdc })(\text { dabco })_{\mathbf{0 . 5}}\right]_{\boldsymbol{n}}$ (4). The previously reported procedure $^{12 b}$ was modified and microwave-assisted synthesis was used to obtain $\left[\mathrm{Ni}(\text { bdc })(\text { dabco })_{0.5}\right]_{n}$. $\mathrm{Ni}\left(\mathrm{NO}_{3}\right)_{2} \cdot 6 \mathrm{H}_{2} \mathrm{O}(0.58 \mathrm{~g}$, $2 \mathrm{mmol})$, terephthalic acid $(0.111 \mathrm{~g}, 0.67 \mathrm{mmol})$ and dabco $(0.299 \mathrm{~g}, 2.67 \mathrm{mmol})$ were dissolved in 5, 12, and $5 \mathrm{ml}$ of DMF, respectively. The solutions of the starting materials were then placed into a $45 \mathrm{ml}$ microwave tube equipped with a Teflon cap. The reaction was carried out at $110{ }^{\circ} \mathrm{C}$ for $2 \mathrm{~h}$ (heating time: $5 \mathrm{~min}$ ) and a power of $200 \mathrm{~W}$. The product formed was washed 3 times with DMF. After solvent exchange with DCM 5 times over 3 days, the product was activated at $120{ }^{\circ} \mathrm{C}$ for
24 hours. Yield: $0.133 \mathrm{~g}\left(72 \%\right.$ based on $\mathrm{H}_{2}$ bdc). Elemental analysis for $\left[\mathrm{Ni}\left(\mathrm{C}_{8} \mathrm{H}_{4} \mathrm{O}_{4}\right)\left(\mathrm{C}_{6} \mathrm{H}_{12} \mathrm{~N}_{2}\right)_{0.5}\right] \cdot 1.2 \mathrm{H}_{2} \mathrm{O}$ calcd: $\mathrm{C} 43.96, \mathrm{H}$ 4.17, N 4.66; found: C 43.86, H 3.79, N 4.6.

Synthesis of $\left[\mathrm{Ni}(\mathrm{ndc})(\mathrm{dabco})_{0.5}\right]_{n}$ (DUT-8(Ni) (5 and 6). $\left[\mathrm{Ni}(\text { ndc })(\text { dabco })_{0.5}\right]_{\text {rrigid }}(5)^{12 c}$ was synthesized using the ultrasound-assisted technique. Typically, $\mathrm{Ni}\left(\mathrm{NO}_{3}\right)_{2} \cdot 6 \mathrm{H}_{2} \mathrm{O}(0.434 \mathrm{~g}$, $1.49 \mathrm{mmol})$, 2,6-naphthalenedicarboxylic acid $(0.294 \mathrm{~g}$, $1.36 \mathrm{mmol})$ and dabco $(0.336 \mathrm{~g}, 2.99 \mathrm{mmol})$ were dissolved in $27 \mathrm{ml} \mathrm{DMF}$ and transferred into a $50 \mathrm{ml}$ Schott bottle. The mixture was reacted in an ultrasonic bath for $50 \mathrm{~min}$. After decantation, the solid was washed 3 times with DMF and exchanged with DCM 6 times over 3 days. The activation of the product was conducted at $120{ }^{\circ} \mathrm{C}$ for 24 hours. Yield: $0.384 \mathrm{~g}$ (86\% based on $\mathrm{H}_{2}$ ndc). Elemental analysis for $\left[\mathrm{Ni}\left(\mathrm{C}_{12} \mathrm{H}_{6} \mathrm{O}_{4}\right)\right.$ $\left.\left(\mathrm{C}_{6} \mathrm{H}_{12} \mathrm{~N}_{2}\right)_{0.5}\right]$ calcd: $\mathrm{C} 54.77, \mathrm{H} \mathrm{3.68,} \mathrm{N} \mathrm{4.26;} \mathrm{found:} \mathrm{C} 54.34, \mathrm{H}$ 3.91, N 4.41 .

The synthesis of $\left[\mathrm{Ni}(\mathrm{ndc})(\mathrm{dabco})_{0.5}\right]_{n-}$ flexible (6) was performed by adapting procedures reported in ref. 12c. Yield: $0.360 \mathrm{~g}\left(80 \%\right.$ based on $\mathrm{H}_{2}$ ndc). Elemental analysis for [ $\mathrm{Ni}$ $\left.\left(\mathrm{C}_{12} \mathrm{H}_{6} \mathrm{O}_{4}\right)\left(\mathrm{C}_{6} \mathrm{H}_{12} \mathrm{~N}_{2}\right)_{0.5}\right] \cdot 0.3 \mathrm{H}_{2} \mathrm{O}$ calcd: $\mathrm{C}$ 53.88, H 3.81, N 4.19; found: C 54.23, H 3.78, N 4.19.

Synthesis of $\left[\mathrm{Ni}(\text { bpdc)(dabco })_{0.5}\right]_{n}$ (DUT-128) (7). Compound 7 was obtained by reacting $\mathrm{Ni}\left(\mathrm{NO}_{3}\right)_{2} \cdot 6 \mathrm{H}_{2} \mathrm{O}(0.58 \mathrm{~g}, 2 \mathrm{mmol})$, 4,4'-biphenyldicarboxylic acid $(0.242 \mathrm{~g}, 2 \mathrm{mmol})$ and dabco $(0.168 \mathrm{~g}, 1.5 \mathrm{mmol})$ that were formerly dissolved in 5, 50, and $5 \mathrm{ml}$ of DMF, respectively. All starting materials were mixed in a $100 \mathrm{ml}$ Schott bottle with a Teflon cap and heated in an oven at $120{ }^{\circ} \mathrm{C}$ for 2 days. The green product was filtered, washed with DMF and exchanged with DCM before being finally filtered under argon and activated at room temperature for 24 hours. Yield: $0.314 \mathrm{~g}$ (44\% based on $\mathrm{H}_{2}$ bpdc). Elemental analysis for $\left[\mathrm{Ni}_{2}\left(\mathrm{C}_{14} \mathrm{O}_{4} \mathrm{H}_{8}\right)_{2}\left(\mathrm{C}_{6} \mathrm{H}_{12} \mathrm{~N}_{2}\right)\right] \cdot 1.5 \mathrm{H}_{2} \mathrm{O}$ calcd: $\mathrm{C} 54.59, \mathrm{H}$ 4.62, N 3.63; found: C 54.35, H 4.37, N 3.5.

\section{Catalytic studies}

Catalytic tests were performed in a $25 \mathrm{ml}$ stainless steel reactor equipped with a magnetic stirrer. Prior to the catalytic experiments, the reactor was loaded with the desired catalysts and the system was evacuated overnight. While flushing the system with ethylene, $\mathrm{Et}_{2} \mathrm{AlCl}$ and $10 \mathrm{ml}$ of toluene as the solvent were injected into the reactor. The vessel was then pressurized with ethylene to the target pressure, and the pressure was maintained by continuous feeding of ethylene. After a certain period of time, the reactions were stopped by turning off the stirrer and ethylene feed. The reactor was cooled down immediately by the $\mathrm{NaCl} /$ ice mixture to condense all gasses produced during the reaction. $n$-Dodecane was added to the reaction solution as the internal standard and water was added to decompose $\mathrm{Et}_{2} \mathrm{AlCl}$. The organic part was immediately analyzed by GC/MS to quantify the oligomers. After each reaction, the reactor was washed with concentrated $\mathrm{HCl}$.

\section{Ethylene consumption and catalysts' lifetime experiments}

For ethylene consumption experiments, the reactor was loaded with activated catalysts and evacuated overnight. $\mathrm{Et}_{2} \mathrm{AlCl}$ and $10 \mathrm{ml}$ of toluene were then loaded into the reactor under an 
ethylene atmosphere. The ethylene pressure was then increased to the desired pressure. The ethylene pressure drop during the reaction was recorded by using a HEISE ST-2H pressure and temperature detector for 1 hour of reaction. The catalysts' lifetime was determined by the cyclic experiment of ethylene consumption as described above five times without opening the autoclave.

\section{Conflicts of interest}

There are no conflicts to declare.

\section{Acknowledgements}

USFA acknowledges Lembaga Pengelola Dana Pendidikan (LPDP) Indonesia for the financial support.

\section{References}

1 Strategic Report - Light Linear Alpha Olefin Market Study | IHS Markit, https://ihsmarkit.com/products/strategicreport-alpha-olefin.html, (accessed 9 April 2018).

2 Y. V. Kissin, in Kirk-Othmer Encyclopedia of Chemical Technology, John Wiley \& Sons, Inc., Hoboken, NJ, USA, 2015, pp. 1-25.

3 A. Finiels, F. Fajula and V. Hulea, Catal. Sci. Technol., 2014, 4, 2412-2426.

4 (a) J. Skupinska, Chem. Rev., 1991, 91, 613-648; (b) K. Fischer, K. Jonas, P. Misbach, R. Stabba and G. Wilke, Angew. Chem., Int. Ed. Engl., 1973, 12, 943-953; (c) F. Speiser, P. Braunstein and L. Saussine, Acc. Chem. Res., 2005, 38, 784-793.

5 A. Hamieh, R. Dey, B. Nekoueishahraki, M. K. Samantaray, Y. Chen, E. Abou-Hamad and J. M. Basset, Chem. Commun., 2017, 53, 7068-7071.

6 (a) J. R. Severn, J. C. Chadwick, R. Duchateau and N. Friederichs, Chem. Rev., 2005, 105, 4073-4147; (b) J. R. Severn and J. C. Chadwick, Tailor-Made Polymers: Via Immobilization of Alpha-Olefin Polymerization Catalysts, Wiley-VCH Verlag GmbH \& Co. KGaA, Weinheim, Germany, 2008.

7 F. F. Karbach, J. R. Severn and R. Duchateau, ACS Catal., 2015, 5, 5068-5076.

8 P. Preishuber-Pflugl and M. Brookhart, Macromolecules, 2002, 35, 6074-6076.

9 (a) M. Lallemand, A. Finiels, F. Fajula and V. Hulea, Chem. Eng. J., 2011, 172, 1078-1082; (b) M. Lallemand, O. A. Rusu, E. Dumitriu, A. Finiels, F. Fajula and V. Hulea, Appl. Catal., A, 2008, 338, 37-43; (c) A. Martinez, M. A. Arribas, P. Concepcion and S. Moussa, Appl. Catal., A, 2013, 467, 509-518.

10 (a) S. Liu, Y. Zhang, Y. Han, G. Feng, F. Gao, H. Wang and P. Qiu, Organometallics, 2017, 36, 632-638; (b) A. N. Mlinar,
B. K. Keitz, D. Gygi, E. D. Bloch, J. R. Long and A. T. Bell, ACS Catal., 2014, 4, 717-721.

11 (a) B. Liu, S. Jie, Z. Bu and B.-G. Li, RSC Adv., 2014, 4, 62343-62346; (b) J. Canivet, S. Aguado, Y. Schuurman and D. Farrusseng, J. Am. Chem. Soc., 2013, 135, 4195-4198; (c) M. I. Gonzalez, J. Oktawiec and J. R. Long, Faraday Discuss., 2017, 201, 351-367; (d) S. T. Madrahimov, J. R. Gallagher, G. Zhang, Z. Meinhart, S. J. Garibay, M. Delferro, J. T. Miller, O. K. Farha, J. T. Hupp and S. T. Nguyen, ACS Catal., 2015, 5, 6713-6718; (e) Z. Li, N. M. Schweitzer, A. B. League, V. Bernales, A. W. Peters, A. B. Getsoian, T. C. Wang, J. T. Miller, A. Vjunov, J. L. Fulton, J. A. Lercher, C. J. Cramer, L. Gagliardi, J. T. Hupp and O. K. Farha, J. Am. Chem. Soc., 2016, 138, 1977-1982; (f) E. D. Metzger, C. K. Brozek, R. J. Comito and M. Dincă, ACS Cent. Sci., 2016, 2, 148-153; (g) R. J. Comito, K. J. Fritzsching, B. J. Sundell, K. SchmidtRohr and M. Dincă, J. Am. Chem. Soc., 2016, 138, 1023210237; (h) P. Ji, J. B. Solomon, Z. Lin, A. Johnson, R. F. Jordan and W. Lin, J. Am. Chem. Soc., 2017, 139, 11325-11328.

12 (a) P. D. C. Dietzel, B. Panella, M. Hirscher, R. Blom and H. Fjellvag, Chem. Commun., 2006, 1, 959; (b) P. Maniam and N. Stock, Inorg. Chem., 2011, 50, 5085-5097; (c) N. Kavoosi, V. Bon, I. Senkovska, S. Krause, C. Atzori, F. Bonino, J. Pallmann, S. Paasch, E. Brunner and S. Kaskel, Dalton Trans., 2017, 46, 4685-4695; (d) Y. Du, A. L. Thompson, N. Russell and D. O'Hare, Dalton Trans., 2010, 39, 3384-3395; (e) N. Klein, C. Herzog, M. Sabo, I. Senkovska, J. Getzschmann, S. Paasch, M. R. Lohe, E. Brunner and S. Kaskel, Phys. Chem. Chem. Phys., 2010, 12, 11778.

13 U. S. F. Arrozi, V. Bon, C. Kutzscher, I. Senkovska and S. Kaskel, CCDC 1835717: CSD Communication, 2018.

14 B. B. Snider, in Encyclopedia of Reagents for Organic Synthesis, John Wiley \& Sons, Ltd, Chichester, UK, 2001.

15 Y. Sato, N. Hosaka, H. Inomata and K. Kanaka, Fluid Phase Equilib., 2013, 344, 112-116.

16 (a) K. Tan, N. Nijem, P. Canepa, Q. Gong, J. Li, T. Thonhauser and Y. J. Chabal, Chem. Mater., 2012, 24, 3153-3167; (b) A. C. Kizzie, A. G. Wong-Foy and A. J. Matzger, Langmuir, 2011, 27, 6368-6373; (c) J. Liu, A. I. Benin, A. M. B. Furtado, P. Jakubczak, R. R. Willis and M. D. Levan, Langmuir, 2011, 27, 11451-11456; (d) E. Mangano, J. Kahr, P. A. Wright and S. Brandani, Faraday Discuss., 2016, 192, 181-195.

17 (a) S. A. Svejda, L. K. Johnson and M. Brookhart, J. Am. Chem. Soc., 1999, 121, 10634-10635; (b) R. Y. Brogaard and U. Olsbye, ACS Catal., 2016, 6, 1205-1214.

18 (a) T. J. Kinnunen, M. Haukka, T. T. Pakkanen and T. A. Pakkanen, J. Organomet. Chem., 2000, 613, 257-262; (b) S. A. Svejda and M. Brookhart, Organometallics, 1999, 18, 65-74.

19 J. Guasch, P. D. C. Dietzel, P. Collier and N. Acerbi, Microporous Mesoporous Mater., 2015, 203, 238-244. 